\section{A CASE OF MALIGNANT DISEASE OF THE} PANCREAS.

Bx W. E. FOTHERGILL, M.A., B.Sc., M.B.Edin., Manchester; late House Physician (Gynæcological Department), Edinburgh Royal Infirmary.

THE following case of primary malignant disease of the pancreas presents some striking resemblances to the two described by Dr. Guthrie Rankin in the BrITISH MEDICAL JoURNAL of May 11 th, 1895 , and, like them, it differs from the classical descriptions of the condition.

On February 26th I saw, for Dr. Darling, of Edinburgh, Miss A., aged 53, a well nourished and healthy looking woman. She was dressed, sitting on a chair, and leaning over a basin. Between paroxysms of pain in the upper part of the abdomen she made ineffectual attempts to vomit. She had suffered from a similar attack in September, 1894, after which she had been somewhat jaundiced. The passage of gall stones was diagnosed. Great abdominal tenderness remained for the next few days, and there was threatened obstruction of the bowels, which was finally overcome by enemata. There was then some diarrhcea. The stools were all examined for gall stones, but none were seen; the motions were high coloured, and contained no fat.

The patient having become less fleshy, and the abdominal tenderness having disappeared, palpation now revealed a solid tumour in the epigastric and umbilical regions. It was surrounded by an area giving a clear percussion note, so being distinct from the liver, which was normal in size. There was no jaundice. The urine contained abundant sugar. Malignant disease affecting the pancreas was now diagnosed, but in the course of the week the patient had several violent rigors, which she attributed to chills on getting out of bed. She was on a milk diet, and there was now no disturbance of digestion. She slept very badly, and lost flesh rapidly. On March 12th a consultation was held, at which it was thought that the condition might be due to suppuration round an impacted gall stone, bearing in mind the history of gall stones in the previous September and the rigors. The surgeon who was asked to see her the same evening found her condition good enough to justify an incision in search of pus.

On March $13^{\text {th }}$ the incision was made, nothing being found but a firm tumour, consisting of infiltrated glands filling the centre of the abdominal cavity. That evening the patient began to vomit blood, and she died on the following day. The abdomen only could be examined post mortem. Its cavity contained very little fluid. The organs were considerably matted together, and the peritoneum was studded in parts with cancerous nodules. With some difficulty the mass of glands in the mesentery and omentum was unravelled, and the pancreas was found completely disorganised by malignant disease. The liver was not infiltrated.

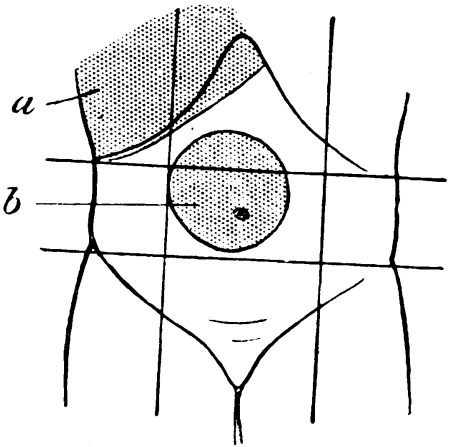

$a$, liver dulness; $b$, tumour dulness.

There were between 200 and 300 gall stones in the gall bladder, which was distended and had thickened walls, but showed no trace of malignancy or acute inflammation. No gall stone was impacted in any duct. The walls of the stomach were so thin and friable, as were those of the duodenum, that it was impossible to avoid tearing them. The vomited blood had apparently entered the stomach from a tear or ulceration near the pylorus. There was a fibroid tumour the size of a hen's egg attached to the fundus of the uterus by a pedicle. This fibroid was of stony hardness, being calcified throughout.

In this case, as in those reported by Dr. Guthrie Rankin, positive symptoms were rapid emaciation after an onset of paroxysmal pain, with deep-seated tenderness. As in his cases, there was absence of fatty stools and of marked digestive disturbance, of jaundice, and of a family history of malignancy. Here, however, glycosuria was a prominent feature of the case. The tumour, on palpation and percussion, was more in the umbilical than in the epigastric region. It gave the impression of being more firm centrally than superficially, which was so. Dr. Rankin's remarks appear to me to apply admirably to this case.

\section{A CASE OF SIMULTANEOUS UTERINE AND EXTRAUTERINE GESTATION.}

\author{
By THOMAS E. MITCHELL, M.B., B.C., \\ Old Hill, Staffs.
}

ON Christmas Day, 1894, I was called to see S. W., aged 30 , whose first child was little over a year old. She was of highly neurotic type, and had a strong family history of insanity. She was suffering from severe pain in the lower part of the abdomen, which came on suddenly. There was no collapse. Her last period had occurred on November 5 th, and she thought she might be pregnant. A vaginal examination revealed no symptoms of hæmatocele or other abnormality, except a slight tendency to prolapse of the bladder. Under rest and opiates the pain speedily subsided, and the patient went on well for some weeks, when she had an attack of influenza. She then complained of difficulty in micturition, but this was attributed to the condition of the bladder, and as she was a very neurotic subject no further vaginal examination was made at this time.

During March she again began to complain of abdominal pain, and the contour of the abdomen differed from that of normal pregnancy. To the right of, and nearly on the level with, the umbilicus, was a rounded globular swelling, clearly defined and resembling a gravid uterus. This was separated by a slight sulcus, from a diffuse, ill-defined swelling to the left of the umbilicus, over which could be heard a distinct souffle. No souffle could be heard at the right of the umbilicus, nor could the foetal heart at this, or any other time, be detected. The os uteri was tilted very much forward, and was so patulous that the finger impinged directly on the internal os. Behind, and to the left of the os, could be felt what was evidently a fotal head; the case was evidently not one of retroflexion, and I regarded it as one of extrauterine fœetation. Dr. Thompson, of Cradley, who saw the case in consultation, considered that there were strong grounds for this conclusion, but from the evidently enlarged condition of the uterus it was not considered advisable to introduce a sound or bougie into the uterus.

The patient was kept in bed, and opium was given for the relief of pain.

On April 27th pains resembling labour pains set in, and next day a bag of membranes presented, on rupturing which a hand, foot, and funis presented. The foot was brought down, and a fotus (5-6 months) was born. The placenta came away naturally, and there was no hæmorrhage. The swelling to the right now contracted to the usual cricket ball size, and that on the left became more central, and a blowing souffle could be heard over its surface.

On April 28th pains again commenced, and opium had to be pushed to its utmost limits to procure any cessation of the intense agony.

On the morning of April 29th, with the assistance of Dr. Griffith, of Netherton, who had occasionally seen the case with me, the patient was put under an anæsthetic, and a digital exploration of the uterus confirmed the view of extraaterine gestation. The chance of operation was offered, but not recommended, to the friends, as the pulse was now 120, and the facial aspect indicative of commencing peritonitis. Operative measures were declined, and the patient sank and died on the morning of April 3oth.

A very limited examination of the body was allowed. This 